\title{
Design of Rectangular Microstrip Patch Antenna for 1.8 GHz Applications
}

\author{
Ali Hanafiah Rambe ${ }^{1}$, Suherman ${ }^{1}$ and Erwin ${ }^{2}$ \\ \{ali3@usu.ac.id\} \\ ${ }^{1}$ Department of Electrical Engineering, Universitas Sumatera Utara, Medan, Indonesia \\ ${ }^{2}$ Master Student of Electrical Engineering, Universitas Sumatera Utara, Medan, Indonesia

\begin{abstract}
Rectangular microstrip patch antenna (RMPA) is a simple antenna, light, and easily to integrate in the system. This paper discusses RMPA design for working on the frequency of $1.8 \mathrm{GHz}$ by using a FR4 substrate with relative permittivity of 4.4 and thickness of $1.6 \mathrm{~mm}$. The optimal of RMPA is assisted by AWR simulator. Based on measurement result, the designed RMPA has VSWR minimum of 1.03 on $1.84 \mathrm{GHz}$ frequency. It has bandwidth of $43 \mathrm{MHz}(1.818-1.861 \mathrm{GHz})$ for $\mathrm{VSWR}<2$. The gain is $4.39 \mathrm{~dB}$
\end{abstract}

Keywords: Rectangular, microstrip, patch.

\section{Introduction}

Rectangular microstrip patch antenna (RMPA) is potentially used any purpose radio as its size is compact and easily integrated to printed board. Microstrip antenna is formed by patch as radiator element, dielectric substrate as isolation to the ground plane and feeding line as depicted in Figure 1. These component developments are in progress to obtain better performances.

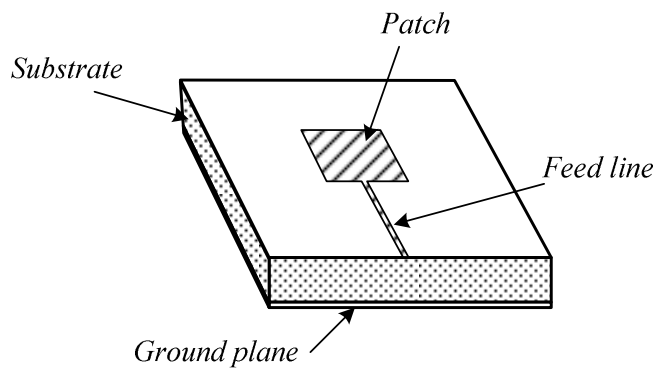

Fig. 1. The RMPA.

Some RMPAs have been designed to work on $2.4 \mathrm{GHz}$ radio (Adrian, 2018; Rambe, A.H., Marlianto, E., Nasruddin M.N., Arnia, 2013). It has also been used for Wireless LAN on $5.21 \mathrm{GHz}$ band (Ahuja, N., Khanna, R., Kaur, 2012). WiMAX applications on frequency band of $8.5 \mathrm{GHz}$ also make use it (Baabdullah, F., Affandi, A., Dobaie, 2016). Recent dual-band long term evolution (LTE) technologies also employ RMPA (Rambe, A.H., Abdillah, 2018). The RMPA demands such as for radio variant is still high (Suherman, 2018). Therefore this paper reports RMPA design for LTE application on frequency band of $1.8 \mathrm{GHz}$. 


\section{Antenna Design}

$$
\begin{gathered}
W=\frac{c}{2 f_{r} \sqrt{\frac{\left(\varepsilon_{r}+1\right)}{2}}} \\
L=L_{e f f}-2 \Delta L \\
L_{e f f}=\frac{c}{2 f_{r} \sqrt{\varepsilon_{r e f f}}} \\
\Delta L=0.412 h \frac{\left(\varepsilon_{r e f}+0.3\right)\left(\frac{W}{h}+0.264\right)}{\left(\varepsilon_{r e f}-0.258\right)\left(\frac{W}{h}+0.8\right)} \\
\varepsilon_{r e f f}=\frac{\varepsilon_{r}+1}{2}+\frac{\varepsilon_{r}-1}{2}\left(\frac{1}{\sqrt{1+12 h / W}}\right)
\end{gathered}
$$

Theoretically, RMPE design can be approximated by using mathematical equations 1-5 (Balanis, 2005):

where $c$ is light speed $3 \times 10^{8} \mathrm{~m} / \mathrm{s}, \quad \square_{r}$ substrate dielectric constant, $f_{r}$ resonant frequency, $h$ substrate thickness, $\quad L_{\text {eff }}$ effective patch length, $\square L$ additional patch length, and $\square$ reff effective substrate dielectric constant.

Based on the aforementioned calculations, by using FR4 substrate with relative permittivity of 4.4 and thickness $1.6 \mathrm{~mm}$, design on frequency of $1.8 \mathrm{GHz}$ requires microstrip size with $51 \mathrm{~mm}$ width and $39 \mathrm{~mm}$ length.

\section{Simulation Results}

Figure 2 shows the initial voltage standing wave ratio (VSWR) of the designed RMPA based on mathematical calculations.

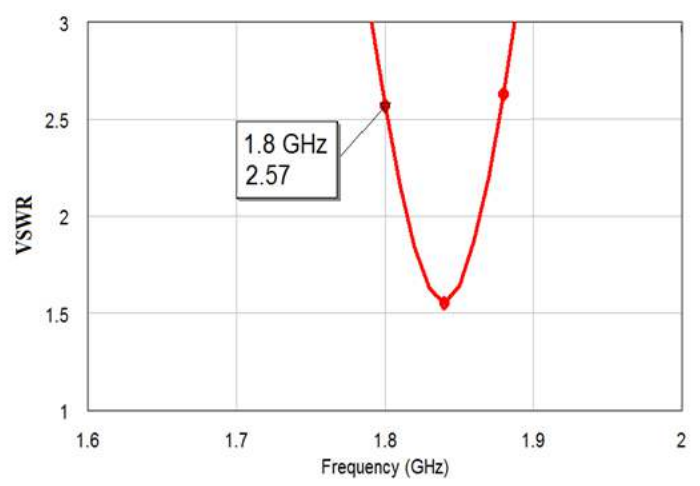

Fig. 2.VSWR simulation result of the first design.

In order to obtain better performances, the VSWR should be adjusted to be as close as to 1 on the desired $1.8 \mathrm{GHz}$. The adjustment is applied to the length of feed line, the width and 
the length of substrate and the width of patch. The VSWR as result feed line adjustment is shown in Figure 3.

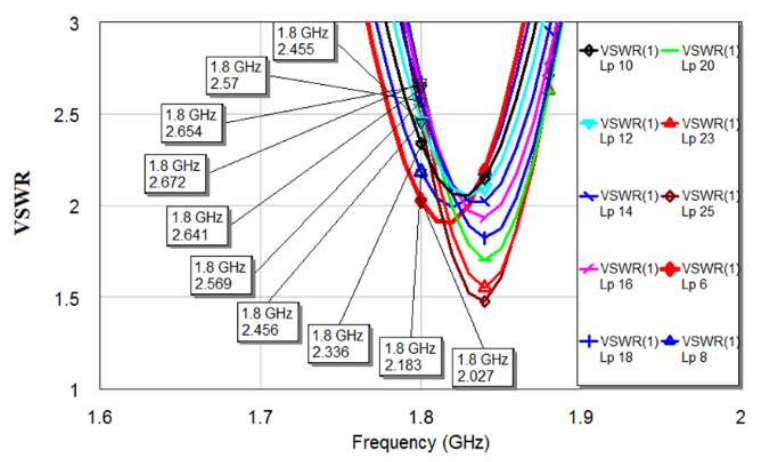

Fig. 3.VSWR graph for feed line adjustment.

Based on feed line adjustment result, for frequency of $1.8 \mathrm{GHz}$, feed line length $6 \mathrm{~mm}$ produces VSWR 2.027. Next is to adjust the length and width of substrate as shown in Figure 4 and Figure 5.

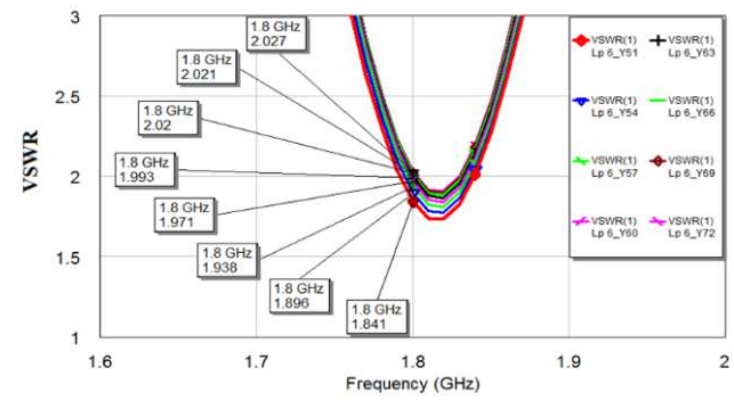

Fig. 4.VSWR graph for substrate length adjustment.

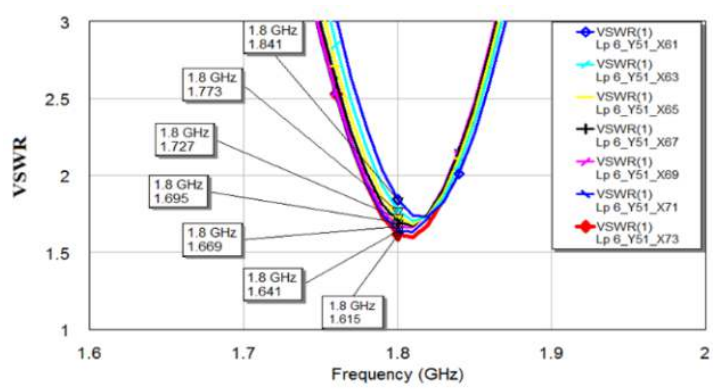

Fig. 5.VSWR graph for substrate width adjustment. 
Based on adjustments of the length and width of substrate, the substrate size of $51 \times 73$ $\mathrm{mm} 2$ is able to produce optimal VSWR 1.615. The iteration for width adjustment of the patch is shown in Figure 6.

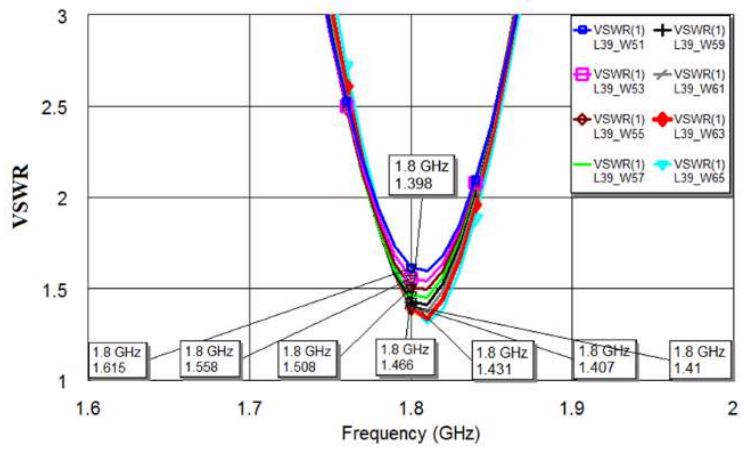

Fig. 6.VSWR graph for patch width adjustment.

By adjusting the width of the patch, the patch size for optimal VSWR is revealed. Figure 6 shows that patch width of $63 \mathrm{~mm}$ is able to provide VSWR 1.41. After the iterations on the simulations as shown in Figure 7, the optimal size is obtained.

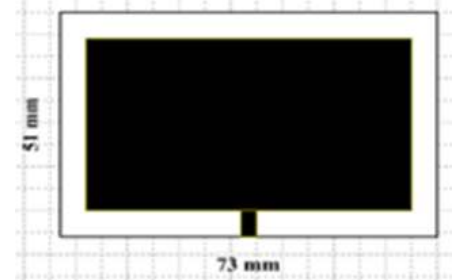

(a) Patch

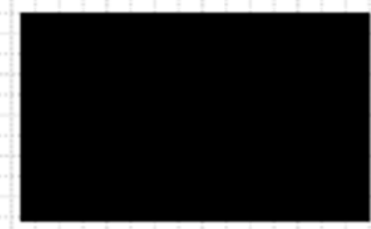

(b) Ground plane

Fig. 7.The optimal RPMA design.

The optimal RPMA design is on substrate size of $51 \times 73 \mathrm{~mm}$. The patch size is $63 \mathrm{~mm}$ length and $39 \mathrm{~mm}$ wide. Feed line size is $3 \times 6 \mathrm{~mm}$.

The VSWR value is almost 1 for centre frequency of $1.8 \mathrm{GHz}$, increasing to 2 at frequency of $1.75 \mathrm{GHz}$ and 2.32 at frequency of $1.85 \mathrm{GHz}$.

The return loss on centre frequency is about $-15.61 \mathrm{~dB}$, rising to $-10 \mathrm{~dB}$ in $1.78 \mathrm{GHz}$ and $1.84 \mathrm{GHz}$. VSWR and return loss are plotted in Figure 8 and Figure 9. 


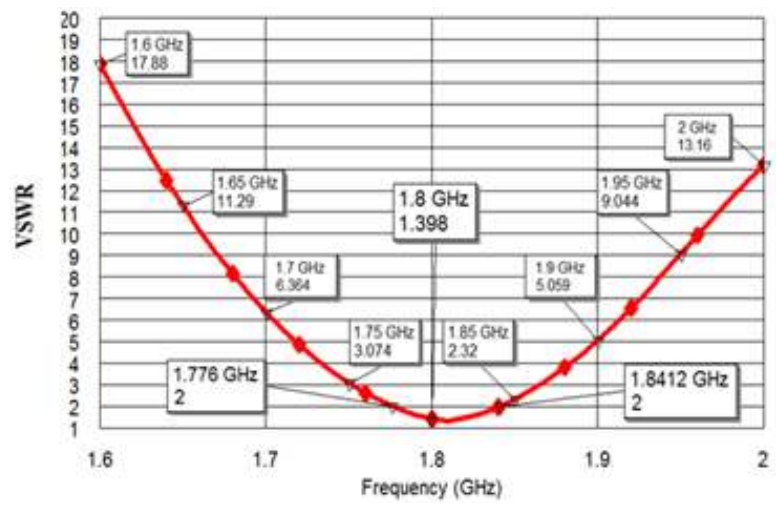

Fig. 8.VSWR simulation of optimal RPMA design.

Based on the obtained parameters as discussed previously, the bandwidth approximation is from $1.776 \mathrm{GHz}$ to $1.8412 \mathrm{GHz}$, about $65.2 \mathrm{MHz}$. At the $1.8 \mathrm{GHz}$ frequency, the antenna VSWR of 1.398 and return loss of $-15.61 \mathrm{~dB}$.

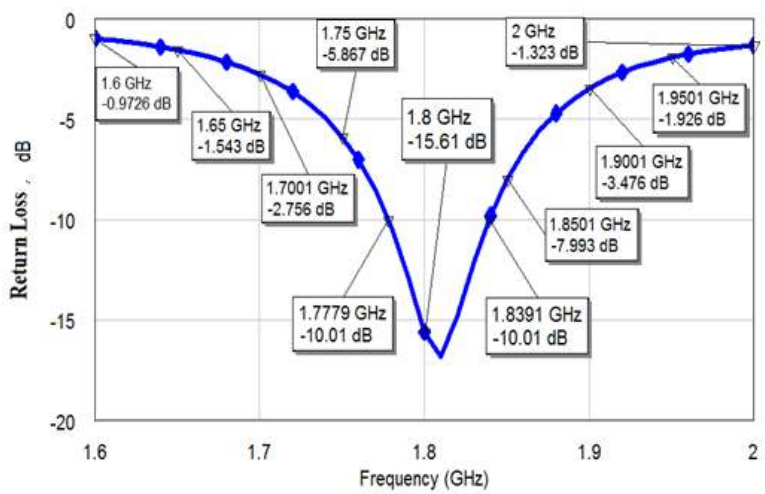

Fig. 9. Return loss simulation of optimal RPMA design.

The antenna radiation pattern is shown in Figure 10, where the maximum radiations are at $0^{\circ}$ and $180^{\circ}$ where gain of $5.406 \mathrm{~dB}$ obtained. Angles of $90^{\circ}$ and $-90^{\circ}$ are the minimum radiation points. 


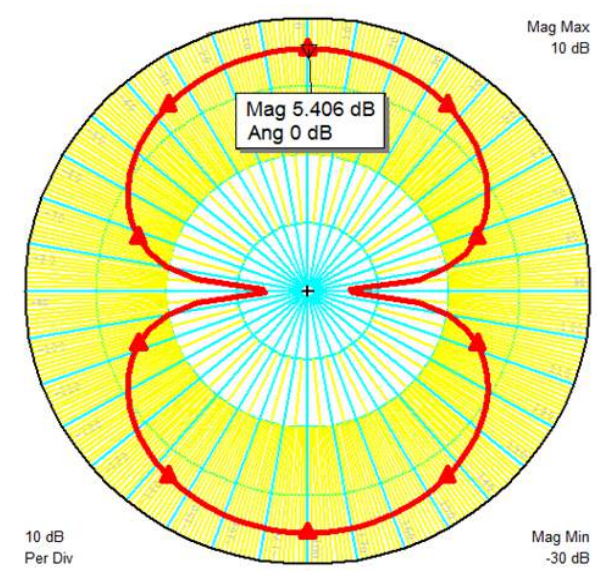

Fig. 10. Radiation pattern simulation of optimal RPMA design.

\section{Measurement Results}

Fabrication of the optimal designed RPMA based on simulation result is depicted in Figure 11. The fabricated RPMA is then measured by using an Anritsu MT8222A vector network analyser (VNA). The SMA $50 \Omega$ connector is employed to connect the antenna and the VNA.

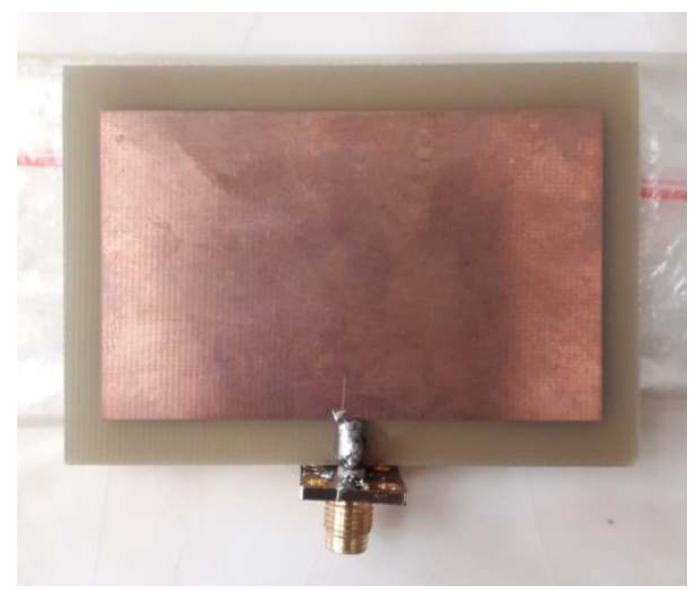

(a) RPMA Patch 


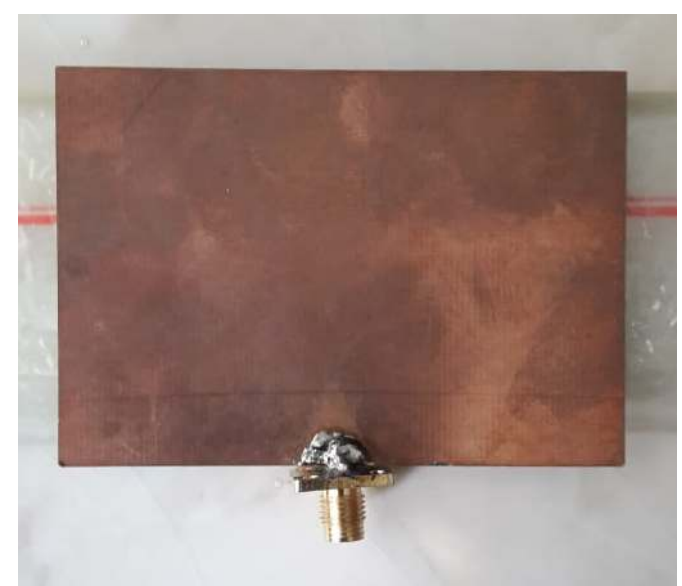

(b) RPMA Ground plane

Fig. 11. The fabricated RPMA.

The VSWR and return loss graphs of the fabricated RPMA are shown in Figure 12 ad Figure 13 .

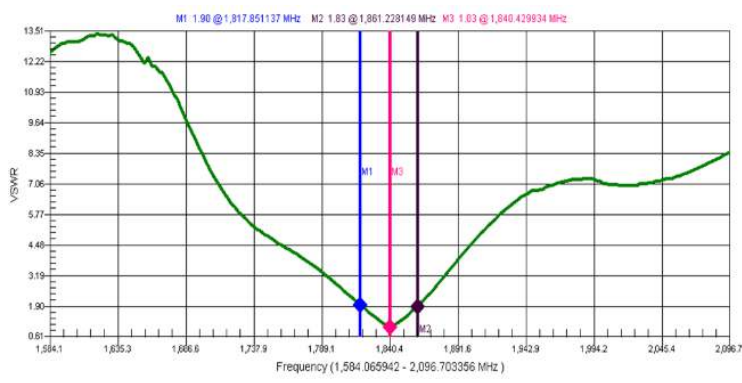

Fig. 12. VSWR measurement.

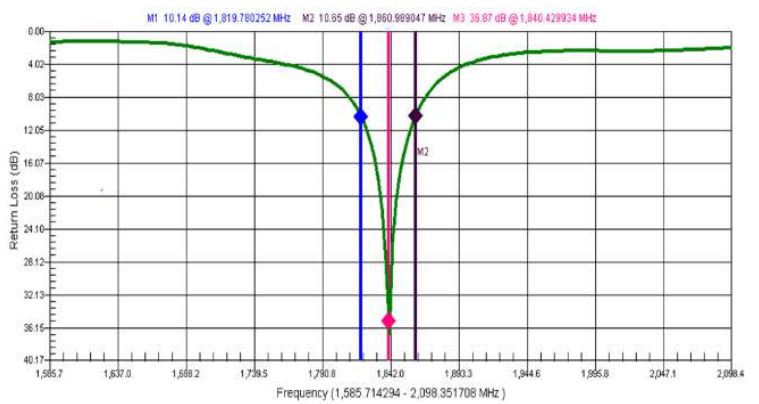

Fig. 13.Return loss measurement. 
Based on VSWR measurement on frequency of $1.818 \mathrm{GHz}$ and $1.861 \mathrm{GHz}$, the values are 1.90 and 1.83 . The lowest VSWR down to 1.03 in frequency of $1.84 \mathrm{GHz}$. The bandwidth achievement for VSWR $\leq 2$ is:

$$
\begin{aligned}
\text { bandwidth } & =\frac{1.861-1.818}{1.840} \times 100 \% \\
& =2.337 \%(43 \mathrm{MHz})
\end{aligned}
$$

While the return losses for frequency of $1.818 \mathrm{MHz}$ and $1.861 \mathrm{MHz}$ are $10.14 \mathrm{~dB}$ and $10.65 \mathrm{~dB}$ subsequently. The lowest return loss is $-36,87 \mathrm{~dB}$ for frequency of $1.840 \mathrm{MHz}$.

The radiation pattern is shown I Figure 14 with maximum gain of $4.39 \mathrm{~dB}$.

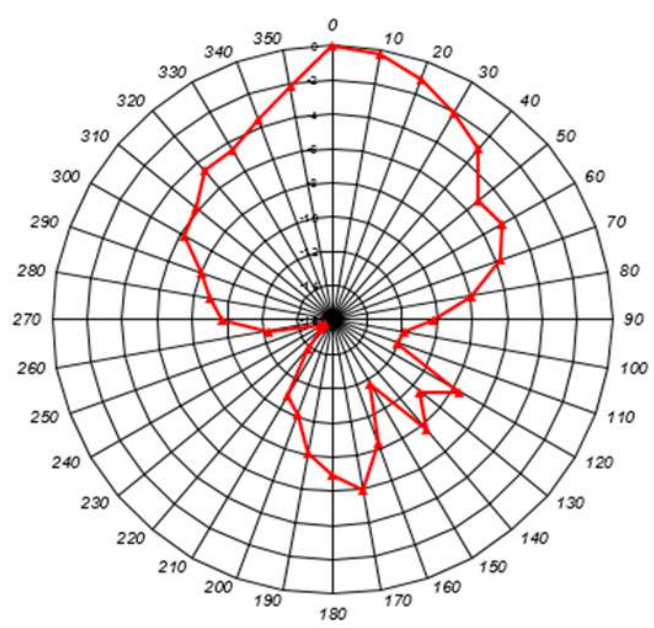

Fig. 14. Radiation pattern measurement.

There are differences between fabricated RMPA measurement result and the simulation. The VSWR comparison is shown in Figure 15.

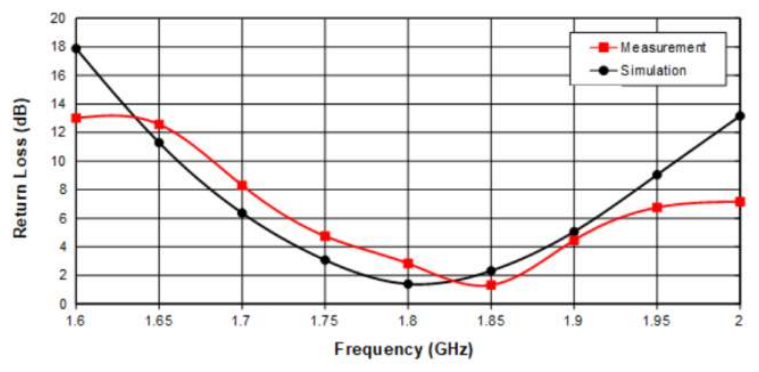

Fig. 15. The simulated and measured VSWR. 
From this figure, it can be seen that the differences exist between the two approaches. This is caused by several factors such as connector and connection problem, untidy soldering or other physical accuracy. Even dough, generally both simulation and realization give the same pattern.

\section{Conclusions}

This paper has shown that RMPA is easily designed for $1.8 \mathrm{GHz}$ frequency. RMPA is simple and requires minimum space. The designed $1.8 \mathrm{GHz}$ antenna only needs $51 \times 73 \mathrm{~mm}$ FR4 substrate to be implemented; with patch size is $63 \mathrm{~mm}$ length and $39 \mathrm{~mm}$ wide, and feed line size is $3 \times 6 \mathrm{~mm}$. This simple construction is able to amplify signal with gain of 4.39 and bandwidth of $43 \mathrm{MHz}$.

\section{Acknowledgements}

This work was supported by Lembaga Penelitian Universitas Sumatera Utara, under the Talenta Research project 2017 (No. 298/UN5.2.3.1/PPM/ KP-TALENTA USU/2017).

\section{References}

[1] Adrian, H. et al. (2018). Computer simulation and implementation of defected ground structure on a microstrip antenna. Journal of Physics: Conference Series, 978(1), 12075 .

[2] Ahuja, N., Khanna, R., Kaur, J. (2012). Design of Single Band Rectangular Patch Antenna for WLAN Application. International Journal of Computer Applications (IJCA).

[3] Baabdullah, F., Affandi, A., Dobaie, A. M. (2016). Design Microstrip Patch Antenna for Wimax Applications at $8.5 \mathrm{Ghz}$. Journal of Electrical and Electronics Engineering.

[4] Balanis, C. A. (2005). Antenna Theory: Analysis and Design, 5nd editio.

[5] Rambe, A.H., Abdillah, K. (2018). A Low Profile Rectangular Patch Microstrip Antenna for Dual-Band Operation of Wireless Communication System. IOP Conference Series: Materials Science and Engineering.

[6] Rambe, A.H., Marlianto, E., Nasruddin M.N., Arnia, F. (2013). Optimizing Rectangular Patch Antenna with Microstrip Line Feed Using Single Stub. International Journal of Engineering Research and Technology, 2(12).

[7] Suherman, S. (2018). WiFi-Friendly Building to Enable WiFi Signal Indoor. Bulletin of Electrical Engineering and Informatics, 7(2). 